University of Nebraska - Lincoln

DigitalCommons@University of Nebraska - Lincoln

$4-8-2004$

Rapid lodine Staining Techniques for Identifying the Waxy

Phenotype in Sorghum Grain and Waxy Genotype in Sorghum

Pollen

Jeffrey F. Pedersen

University of Nebraska-Lincoln, jpedersen1@unl.edu

S.R. Bean

USDA-ARS

Deanna L. Funnell

University of Nebraska-Lincoln, dfunnell2@unl.edu

Robert A. Graybosch

University of Nebraska-Lincoln, bob.graybosch@ars.usda.gov

Follow this and additional works at: https://digitalcommons.unl.edu/plantpathpapers

Part of the Plant Pathology Commons

Pedersen, Jeffrey F.; Bean, S.R.; Funnell, Deanna L.; and Graybosch, Robert A., "Rapid lodine Staining Techniques for Identifying the Waxy Phenotype in Sorghum Grain and Waxy Genotype in Sorghum Pollen" (2004). Papers in Plant Pathology. 31.

https://digitalcommons.unl.edu/plantpathpapers/31

This Article is brought to you for free and open access by the Plant Pathology Department at DigitalCommons@University of Nebraska - Lincoln. It has been accepted for inclusion in Papers in Plant Pathology by an authorized administrator of DigitalCommons@University of Nebraska - Lincoln. 


\title{
Rapid Iodine Staining Techniques for Identifying the Waxy Phenotype in Sorghum Grain and Waxy Genotype in Sorghum Pollen
}

\author{
J. F. Pedersen,* S. R. Bean, D. L. Funnell, and R. A. Graybosch
}

\begin{abstract}
Visual classification of sorghum [Sorghum bicolor (L.) Moench] grain for the waxy phenotype is subjective and can be confounded by genetic background, maturity, environment, and experience of the classifier. Rapid iodine staining methods for identifying the waxy phenotype in sorghum grain and waxy genotypes in sorghum pollen were developed. Mature single sorghum seeds were placed in 48-well micro-plates and crushed. Water was added and the mixture heated to $95^{\circ} \mathrm{C}$ for $1 \mathrm{~h}$ to gelatinize the starch. After cooling, iodine solution was added and color scored after 10 to $60 \mathrm{~s}$ allowing for very high sample throughput. Sorghum pollen was analyzed for waxy genotype by mixing isolated pollen with iodine solution and viewing under a microscope at $40 \times$. Waxy pollen was visually distinguishable from wild-type pollen using freshly collected as well as aged pollen. These methods will allow large-scale screening of both mature sorghum grains as well as sorghum pollen for waxy characteristics.
\end{abstract}

$T$ HE WAXY PHENOTYPE in grains is associated with endosperm containing little or no amylose. Starch in waxy grain is nearly pure amylopectin and the endosperm in sorghum exhibits the appearance of candle wax, hence the designation "waxy" (Rooney and Miller, 1982). The waxy trait has been recognized in sorghum since at least 1933 when the gene symbol $w x$ was assigned to this trait (Karper, 1933). Classification of sorghum lines as waxy or wild type is often a visual assessment of endosperm fracture patterns. Such classification is subjective and can be confounded by genetic background, grain maturity, environment, and by the experience of the classifier. It is also limited in application to mature grain.

Waxy and wild-type grain phenotypes of other grains can be readily distinguished by iodine staining (Nakamura et al., 1995; Neuffer et al., 1997). Wild-type grain usually stains deep blue because of the presence of amylose, and waxy phenotypes usually stain reddish brown. Waxy and wild-type genotypes can also be identified in maize (Zea mays L.) pollen by iodine staining, with wild-type pollen staining dark brown and waxy pollen staining light tan (MaizeDB, 2003). In sorghum, iodine

J.F. Pedersen, D.L. Funnell, and R.A. Graybosch, USDA-ARS, NPA Wheat, Sorghum and Forage Research, 344 Keim Hall, University of Nebraska-Lincoln, Lincoln, NE 68583-0937; S.R. Bean, USDA-ARS, NPA, GMPRC, 1515 College Avenue, Manhattan, KS, 66502. Joint contribution of the USDA-ARS and the Univ. of Nebraska Agric. Exp. Stn. as Paper no. 14242, Journal Series, Nebraska Agric. Exp. Stn. Mention of a trademark, proprietary product, or a vendor does not constitute a guarantee or warranty of the USDA or the University of Nebraska and does not imply its approval to the exclusion of other products or vendors that may also be suitable. Received 8 September 2003. *Corresponding author (jfp@unlserve.unl.edu).

Published in Crop Sci. 44:764-767 (2004).

(c) Crop Science Society of America

677 S. Segoe Rd., Madison, WI 53711 USA is less indicative of phenotype since iodine binding is reduced in lines with corneous endosperm (Cagampang and Kirleis, 1985). However, such sorghum starch can be made more amenable to iodine staining by gelatinization. Our objective was to adapt iodine staining techniques to sorghum grain and pollen for rapid and objective identification of waxy and wild-type phenotypes.

\section{MATERIALS AND METHODS \\ Iodine Staining of Sorghum Grain}

Single sorghum seeds of known waxy (BTx630, TxAGR1, RTx2907, B9307, B94C274) and wild-type (RTx430, Wheatland, Redlan) genotypes grown at the University of Nebraska Field Laboratory at Ithaca, NE, in 2002 were placed in Costar 48-well micro-plates (Corning Inc., Corning, NY) and coarsely crushed with a HyPure Seed Crusher (PerkinElmer Wallac Inc., Norton, $\mathrm{OH}$ ). One milliliter $\mathrm{H}_{2} \mathrm{O}$ was added to each cell and the samples were heated in a $95^{\circ} \mathrm{C}$ oven for $1 \mathrm{~h}$ followed by cooling to room temperature to gelatinize the starch. Fifty microliters of iodine stain solution $(2.5 \mathrm{~g} \mathrm{KI}, 250 \mathrm{mg} \mathrm{I}, 125 \mathrm{~mL}$ $\mathrm{H}_{2} \mathrm{O}$ ) was added to each well and the color reaction scored in 10 to $60 \mathrm{~s}$. Wells developing dark blue were scored as wild type, and wells developing various shades of magenta were scored as waxy. The protocol was repeated in a second laboratory to verify results.

\section{Iodine Staining of Sorghum Pollen}

\section{Fresh Pollen}

Fresh pollen was collected from greenhouse-grown known waxy (BTx630, TxAGR1) and wild-type (RTx430, Wheatland) genotypes at pollen dehiscence (0800-1000 h). Pollen was collected by shaking a panicle on a clean sheet of paper, pouring the pollen into a $1.5-\mathrm{mL}$ microcentrifuge tube, and covering the pollen with $0.5 \mathrm{~mL} 70 \%(\mathrm{v} / \mathrm{v})$ ethanol. Samples were stored in a refrigerator at $4^{\circ} \mathrm{C}$.

Before subsampling for staining, pollen was suspended in the ethanol solution by shaking the microcentrifuge tube, and $5 \mu \mathrm{L}$ transferred to another microcentrifuge tube. Ten microliters of the iodine stain solution $(2.5 \mathrm{~g} \mathrm{KI}, 250 \mathrm{mg} \mathrm{I}, 125 \mathrm{~mL}$ $\mathrm{H}_{2} \mathrm{O}$ ) was added to the $5 \mu \mathrm{L}$ of pollen suspension, and mixed. The stained suspension was placed on a microscope slide and examined at $40 \times$ with a high resolution dissecting microscope with illumination provided from above and below the slide. Pollen staining dark brown was scored as wild type. Pollen staining light tan or yellow was scored as waxy.

\section{Aged Pollen}

Aged pollen was collected from closed pollination bags that had been placed on greenhouse-grown known waxy (BTx630) and wild-type (RTx430, Wheatland, BTx623, and Redlan) genotypes 38 to $42 \mathrm{~d}$ before pollen collection. Aged pollen was stored and stained as above. Staining of both fresh and aged pollen was repeated in a second laboratory to verify results. 
$\begin{array}{llllllll}1 & 2 & 3 & 4 & 5 & 6 & 7 & 8\end{array}$

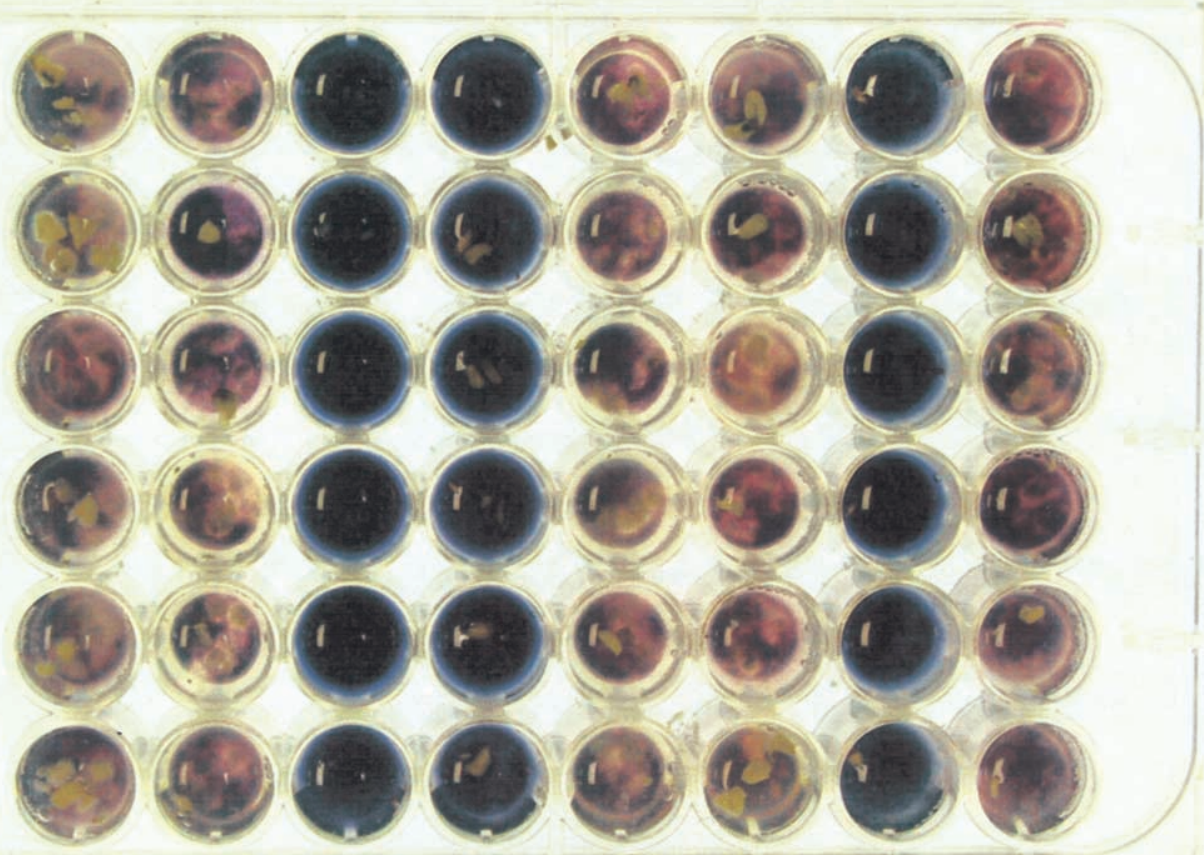

Fig. 1. Iodine staining of crushed and gelatinized individual sorghum seeds. One genotype per column, one seed per cell. Genotypes in Columns 1 through 8, respectively, are: BTx630, TxAGR1, RTx430, Wheatland, B9307, B94C274, Redlan, RTx2907.
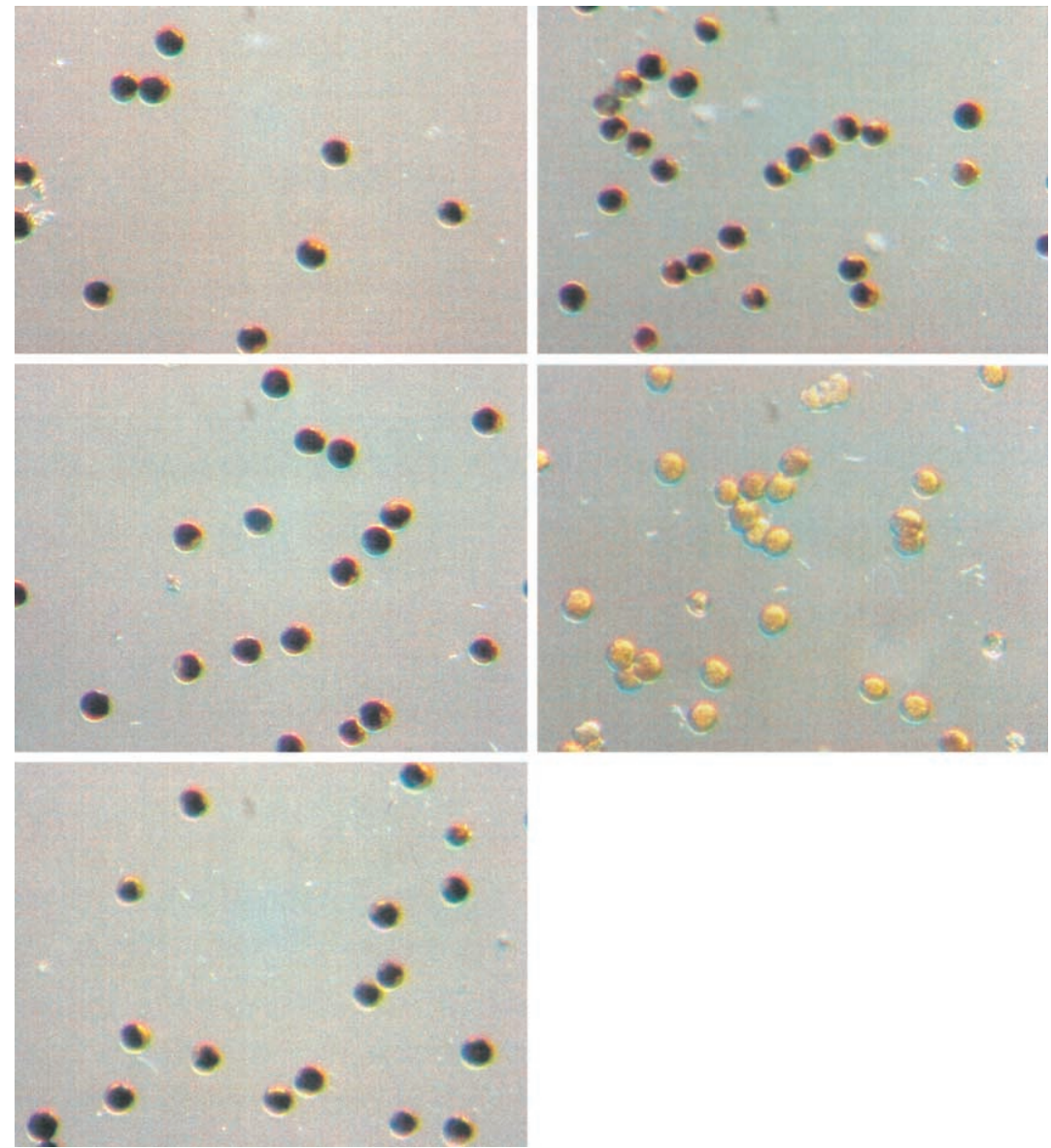

Fig. 3. Iodine staining of 30-d-old pollen magnified $40 \times$. BTx630, RTx430, Wheatland (from top to bottom, left column), BTx623, Redlan (from top to bottom, right column). 

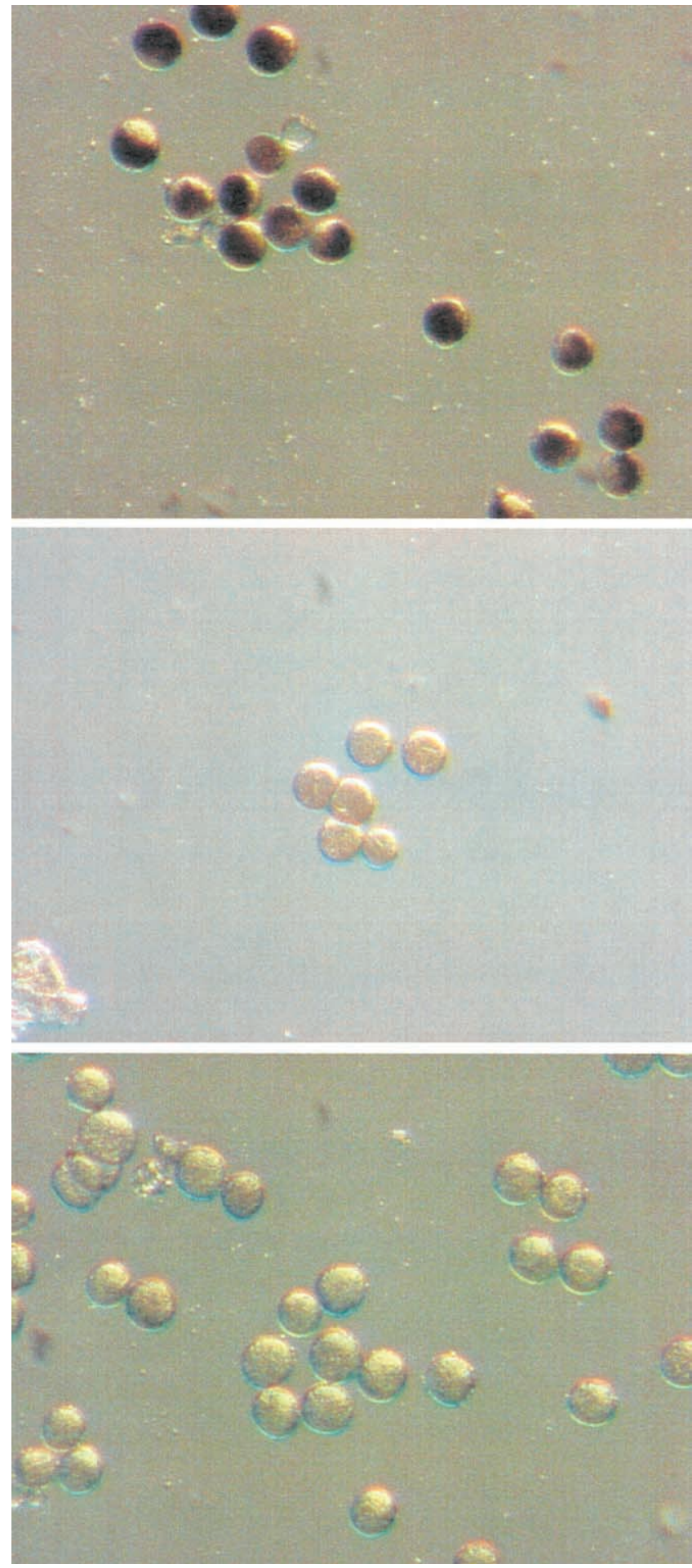

Fig. 2. Iodine staining of fresh pollen magnified $40 \times$. BTx630 (top), BTxAGR1 (middle), and RTx430 (bottom).

\section{RESULTS AND DISCUSSION Iodine Staining of Sorghum Grain}

Iodine staining of known sorghum genotypes was consistent with expectations on the basis of pedigree (Fig. 1). It was necessary to read color development quickly be- cause some sorghum samples fade in color or clear rapidly following addition of the iodine stain. Identical results were obtained in both laboratories.

The use of the microplate and HyPure Seed Crusher is very effective at isolating single seeds for analyses and processing large numbers of samples in bulk. In the micro-plate shown (Fig. 1), we classified 6 seeds per line to visualize uniformity. The number of lines that can be screened per hour will be dependent upon number of seed needed to represent a line, or for a particular experimental protocol. Using a small oven capable of holding only four micro-plates and single-tip pipettes, we could easily process and stain 384 seeds per hour.

\section{Iodine Staining of Sorghum Pollen}

Iodine staining of freshly dehisced pollen (Fig. 2) and approximately 30-d old pollen (Fig. 3) of known sorghum genotypes was consistent with expectations on the basis of pedigree. Maize pollen can be kept stored in $70 \%$ alcohol indefinitely (Christine Chase, personal communication, 2003), and we have observed sorghum pollen to store for at least 3 mo without observable changes in reaction to iodine staining.

Initial attempts to repeat the protocol in a second laboratory produced ambiguous results that were caused by differences in microscopes and illumination of the samples. Following adjustment of illumination to optimize color differences in stained pollen, identical results were obtained in the second laboratory. It is recommended that users of this pollen staining technique adjust microscopes and illumination to maximize color differentiation using pollen from known wild-type and waxy lines before collecting data on experimental samples.

The ability to stain and classify 1-mo old pollen captured in pollinating bags makes pollen collection a schedulable activity, instead of a daily survey for pollen dehiscense and collection, if appropriate for experimental objectives (i.e., large scale screening). For other experimental applications, the haploid condition of pollen makes direct genotype classification possible at anthesis since homozygous individuals shed either $w x$ or $W x$ pollen and heterozygous individuals shed a segregating mixture of $w x$ and $W x$ pollen. By being able to classify genotype at anthesis, genetic studies and germplasm enhancement programs can be more efficient in management of generations needed to accomplish objectives.

\section{CONCLUSIONS}

These iodine-staining techniques permit rapid, repeatable, and objective classification of sorghum grain and pollen for waxy or wild-type phenotype. They also provide considerable flexibility for sampling in experimental protocols; and when using fresh pollen, they allow identification of the genotype of individuals at anthesis, which can be used to make genetic experiments and germplasm improvement more efficient. 


\section{REFERENCES}

Cagampang, G.B., and A.W. Kirleis. 1985. Properties of starches isolated from sorghum floury and corneaous endosperm. Starch 37: 253-257.

Karper, R.E. 1933. Inheritance of waxy endosperm in sorghum. J. Hered. 24:257-262.

MaizeDB. 2003. Non-waxy and waxy pollen stained with iodine, showing dark brown $\mathrm{Wx1}$ pollen and tan wx1 pollen. http://www.agron. missouri.edu/db_images/Variation/cd7101-3161-0708/76.jpg (Verified 16 January 2004).
Nakamura, T., M. Yamamori, H. Hirano, S. Hidaka, and T. Nagamine. 1995. Production of waxy (amylose-free) wheats. Mol. Gen. Genet. 248:253-259.

Neuffer, M.G., E.H. Coe, and S.R. Wessler. 1997. Mutants of maize. Cold Spring Harbor Press, Plainview, NY.

Rooney, L.W., and F.R. Miller. 1982. Variation in the structure and kernel characteristics of sorghum. p. 143-161. In L.W. Rooney and D.S. Murty (ed.) Proc. International Symposium on Sorghum Grain Quality. Oct. 28-31, 1981. International Crops Research Institute for the Semi-Arid Tropics, Patancheru. A.P., India. 